Z Gerontol Geriat 2021 · 54:37

https://doi.org/10.1007/s00391-020-01834-y

Online publiziert: 4 . Januar 2021

(c) Der/die Autor(en) 2021

Kerstin Bilda ${ }^{1}$. Stefan Stricker ${ }^{2}$

'Hochschule für Gesundheit, Bochum, Deutschland

${ }^{2}$ Integrierte Versorgung, Stiftung Deutsche Schlaganfall-Hilfe, Gütersloh, Deutschland

\title{
Erratum zu: Geschulte Schlaganfall-Helferinnen und Schlaganfall-Helfer
}

Erratum zu:

Z Gerontol Geriat 2020

https://doi.org/10.1007/s00391-020-018 16-0

Der Artikel „Geschulte Schlaganfall-Helferinnen und Schlaganfall-Helfer" von Kerstin Bilda und Stefan Stricker wurde ursprünglich am 24. November 2020 ohne „Open Access“ online auf der Internetplattform des Verlags publiziert. Die Autoren haben sich jedoch nachträglich für eine „Open Access“-Veröffentlichung entschieden. Das Urheberrecht des Artikels wurde deshalb am 9. Dezember 2020 in (c) Der/die Autor(en) 2020 geändert. Der Artikel wird nun unter der Creative Commons Namensnennung 4.0 International Lizenz veröffentlicht, welche die Nutzung, Vervielfältigung, Bearbeitung, Verbreitung und Wiedergabe in jeglichem Medium und Format erlaubt, sofern Sie den/die ursprünglichen Autor(en) und die Quelle ordnungsgemäß nennen, einen Link zur Creative Commons Lizenz beifügen und angeben, ob Änderungen vorgenommen wurden. Die in diesem Artikel enthaltenen Bilder und sonstiges Drittmaterial unterliegen ebenfalls der genannten Creative Commons Lizenz, sofern sich aus der Abbildungslegende nichts anderes ergibt. Sofern das betreffende Material nicht unter der genannten Creative Commons Lizenz steht und die betreffende Handlung nicht nach gesetzlichen Vorschriften erlaubt ist, ist für die oben aufgeführten Weiterverwendungen des Materials die Einwilligung des jeweiligen Rechteinhabers einzuholen. Weitere Details zur Lizenz entnehmen Sie bitte der Lizenzinfor- mation auf http://creativecommons.org/ licenses/by/4.0/deed.de.

\section{Korrespondenzadresse}

Prof. Dr. phil. Kerstin Bilda

Hochschule für Gesundheit

Gesundheitscampus 6-8, 44801 Bochum,

Deutschland

kerstin.bilda@hs-gesundheit.de

Open Access. Dieser Artikel wird unter der Creative Commons Namensnennung 4.0 International Lizenz veröffentlicht, welche die Nutzung, Vervielfältigung, Bearbeitung, Verbreitung und Wiedergabe in jeglichem Medium und Format erlaubt, sofern Sie den/die ursprünglichen Autor(en) und die Quelle ordnungsgemäß nennen, einen Link zur Creative Commons Lizenz beifügen und angeben, ob Änderungen vorgenommen wurden.

Die in diesem Artikel enthaltenen Bilder und sonstiges Drittmaterial unterliegen ebenfalls der genannten Creative Commons Lizenz, sofern sich aus der Abbildungslegende nichts anderes ergibt. Sofern das betreffende Material nicht unter der genannten Creative Commons Lizenz steht und die betreffende Handlung nicht nach gesetzlichen Vorschriften erlaubt ist, ist für die oben aufgeführten Weiterverwendungen des $\mathrm{Ma}$ terials die Einwilligung des jeweiligen Rechteinhabers einzuholen.

Weitere Details zur Lizenz entnehmen Sie bitte der Lizenzinformation auf http://creativecommons.org/ licenses/by/4.0/deed.de.
Die Online-Version des Originalartikels ist unter https://doi.org/10.1007/s00391-020-01816-0 zu finden. 